\title{
Studies on the Relationship between Chronic Fatigue Syndrome and Epstein-Barr Virus in Japan
}

\author{
Kiyoshi KAWAI and Akira KaWAI*
}

\begin{abstract}
Among 1,153 consecutive patients, 22 patients (1.9\%) who complained of chronic fatigue for a period of over 6 monthes without detectable causes were studied. Ten patients $(0.86 \%)$ satisfied the criteria of chronic fatigue syndrome (CFS) and were classified to be definite cases of CFS. The other patients were classified as probable cases. In order to clarify the role of EpsteinBarr virus (EBV) as a cause of CFS, we measured various antibodies for EBV. The definite cases had significantly higher titers of early antigen complex (EA)-IgG than both the probable cases and controls. We proposed the EA-IgG/EBNA ratio as the indicator of activation of EBV and attempted to estimate the degree of fatigue by the EA-IgG/EBNA ratio. The highest ratio value (16.0) of the 22 patients ratios was the most serious case. In general, the ratio correlated with the degree of fatigue. Based on these rasults, it was concluded that a relationship does exist between CFS and EBV.
\end{abstract}

(Internal Medicine 31: 313-318, 1992)

Key words: early antigen antibody (EA-IgG), nuclear antigen antibody (EBNA), viral capcid antigen antibody (VCA-IgG), immune aberrations, stressful life style

\section{Introduction}

Fatigue is a common complaint in primary care, both in Japan and in the U.S.A. (1). However, it is often given only minor consideration by Japanese physicians. When fatigue reduces a patient's daily activity level to less than $50 \%$ of normal for a period of over 6 months, it should then be regarded as a major problem. In 1982 Tobi et al reported a relationship between prolonged atypical illness and persistent Epstein-Barr virus (EBV) infection (2). In the 1980's a few studies demonstrated a causal relationship between EBV and patients with persistent fatigue $(3,4)$. However, other reports denied the existence of a causal relationship between EBV and a chronic mononucleosis-like syndrome which accompanied persistent fatigue (5-8). To avoid conflict, Holmes et al defined chronic fatigue syndrome (CFS) as a specific syndrome complex without implicating EBV as a causative agent (9). They also proposed a working case definition for conducting epidemiologic and clinical studies (9). Recently, most of the CFS patients have been regarded by some physicians as a psychiatric disorder $(10,11)$. To date, the worldwide debate over the etiology and frequency of CFS has not been resolved.

The purpose of this study was to identify cases in our family practice clinic, whose symptoms correspond with the criteria of CFS and verify the existence of a causative relationship between EBV and CFS.

\section{Patients}

From May 1989 till December 1989, 1,153 consecutive patients were seen in our family practice clinic. The patients were all over the age of 20 . We detected 22 patients who had complaints of persistent fatigue for over 6 months and who had no evidence of psychiatric disorders, especially depression, or other detectable disorders. Of these 22 patients, 10 patients satisfied the criteria for CFS of Holmes et al. (9) and were classified as "definite cases". The other cases were classified as "probable cases". Sixteen non-fatigued patients, who did not satisfy the criteria of CFS, were selected as controls and were matched demographically with a fatigued patient. Age, sex and prevalence within the subgroups of persistent fatigue and controls are shown in Table 1 . The majority of patients were female, with

From the Kawai Internal Medicine Clinic, Tokyo and * Department of Medicine, Keio University, School of Medicine, Tokyo

Received for publication January 16, 1991; Accepted for publication August 12, 1991

Reprint requests should be addressed to Kiyoshi Kawai, M. D., the Kawai Internal Medicine Clinic, 3-1-11 Kamiogi, Suginami-ku, Tokyo 167, Japan 


\section{Kawai and Kawai}

Table 1. Prevalence of Chronic Fatigue Syndrome in Our Family Practice

\begin{tabular}{|c|c|c|c|c|c|c|}
\hline & \multirow[b]{2}{*}{ No. } & \multicolumn{2}{|c|}{ Sex } & \multirow{2}{*}{$\begin{array}{l}\text { Age, yrs } \\
\text { (Range) }\end{array}$} & \multirow{2}{*}{$\begin{array}{c}\text { Age, yrs } \\
\text { (Mean) }\end{array}$} & \multirow{2}{*}{$\begin{array}{c}\text { Prevalence, } \% \\
\quad(\mathrm{~N} / 1.153)\end{array}$} \\
\hline & & $\mathrm{F}$ & $\mathrm{M}$ & & & \\
\hline Definite cases & 10 & 9 & 1 & $27-66$ & 45.5 & 0.86 \\
\hline Probable cases & 12 & 10 & 2 & $20-67$ & 39.0 & 1.04 \\
\hline (Total) & 22 & 19 & 3 & $20-67$ & 41.5 & 1.90 \\
\hline Controls & 16 & 15 & 1 & $23 \sim 63$ & 40.3 & \\
\hline
\end{tabular}

an age range of widely from 20 to 67 years old. The prevalence of definite cases was $0.86 \%$ and that of probable cases was $1.04 \%$.

Clinical findings on enrollment of the 10 definite CFS cases are shown in Table 2 . Of these 10 cases, only 2 had a past history of an infectious mononucleosis-like illness. The duration of CFS ranged widely from 7 months to $23 \mathrm{yr}$. The main symptoms other than fatigue were myalgia, headache, arthralgia, dizziness, sore throat, insomnia, backpain, palpitation and paresthesia. The incidence of these symptoms can be seen on Table 2 . Antinuclear antibody (ANA) was tested in 7 cases; 2 cases were positive. Rheumatoid factor (RF) was tested in 7 cases; case No. 3 was equivocal and all other cases were negative. C-reactive protein (CRP) was tested for in 7 cases; case No. 3 was positive and all other cases were negative. From the above-mentioned laboratory data and physical findings, none of the present fatigued patients fulfilled the diagnostic criteria of rheumatoid arthritis (12) or other connective tissue diseases.

\section{Method}

Blood collection was done during the daytime at our office. Blood specimens were sent to Mitsubishi Yuka Laboratory Inc., for same-day processing. The EBV antibody tests included IgG antibody (VCA-IgG) and IgM antibody (VCA-IgM) to viral capcid antigen, IgG antibody to early antigen complex (EA-IgG) and an antibody to Epstein-Barr virus nuclear antigen (EBNA). Immunofluorescence tests were performed using a commercially available slide kit with the above EBV antigens (13). The minimal dilution of sera was $1: 10$ and a titer of $\geqq 1: 10$ was regarded as positive for all antibodies induced by EBV. No cases showed non-specific reaction of the immunofluorescence test due to ANA-positive serum. According to a preliminary study, ANA-positive serum interferred with the antibody test of EBV only in the case of high titers of $>1: 320$.

Lymphocyte phenotype analysis in 6 cases was done with flow cytometry using monoclonal antibodies. The

Table 2. Clinical Findings of the 10 Definite Cases

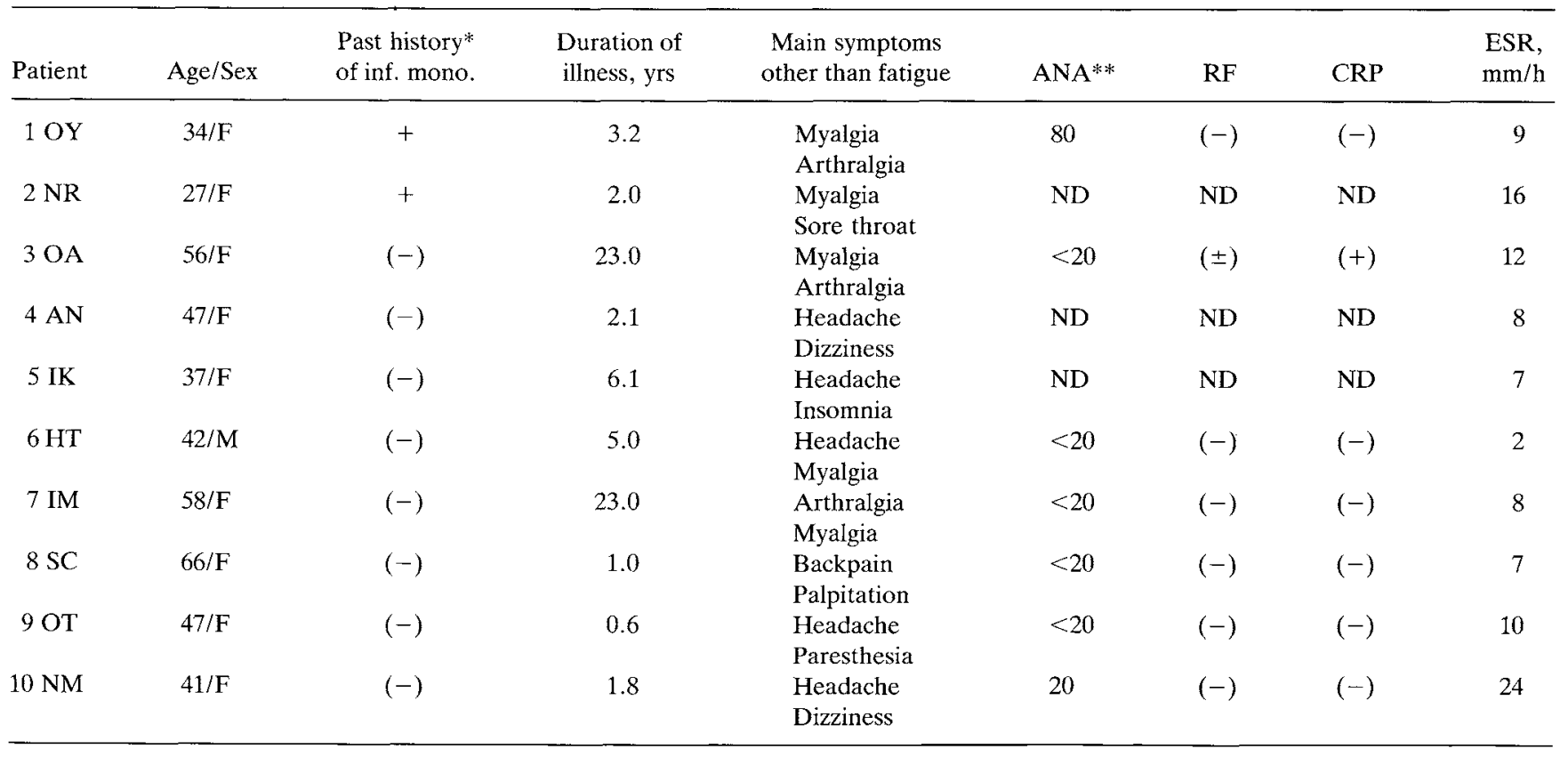

* Past history of infectious mononucleosis-like illness.

** ANA: Anti-nuclear antibody, ND: Not done, RF: Rheumatoid factor, CRP: C-reactive protein, ESR: Erythrocyte sedimentation rate. 
comparisons between the fatigued cases $(n=22)$ and controls $(\mathrm{n}=16)$ were made statistically using Wilcoxen's rank sum test analysis.

\section{Results}

The comparisons of the EBV antibodies in all subjects are shown in Fig. 1. Titers of VCA-IgG in the fatigued cases ranged from 80 to 1,280 (reciprocal of titer), however, the controls ranged from 40 to 640 . The difference between the mean titers was significant $(p<0.08)$. Titers of EA-IgG in the fatigued cases ranged from 10 to 640 and the controls ranged from 10 to only 40 . The difference between the mean titers was even more significant $(p<0.01)$ than that of VCA-IgG. The difference between the mean titers of EBNA was not significant. These results agree with Jones et al (3) and Straus et al (4). Of all subjects only No. 3 , who was the most severely ill, had a positive antibody titer of VCA-IgM (20).

The comparison of VCA-IgG and EA-IgG among the definite cases, probable cases and controls is shown in Fig. 2. We attempted to demonstrate a difference in VCA-IgG and EA-IgG between the two subgroups of fatigued cases. The difference in the mean titers of VCA-IgG between the definite cases and the probable cases was not significant. The difference between the definite cases and controls was significant $(p<0.05)$. The difference in the mean titers of EA-IgG between the definite cases and probable cases was significant $(\mathrm{p}<0.01)$. The difference between the probable cases and controls was not significant. These results indicate the importance of EA-IgG in differentiating the definite cases from the probable cases.

An attempt was made to estimate the degree of fatigue by EA-IgG/EBNA ratio (Fig. 3). All definite cases fell between 2.0 and 16.0 , probable cases between 0.0625 and 2.0, and controls between 0.03125 and 1.0. The difference in the mean titers of EA-IgG/EBNA ratio between the definite cases and probable cases was significant $(p<0.01)$. The difference between the definite cases and controls was also significant. The difference between the probable cases and controls was not significant. The highest value (16.0) was case No. 3, which was the most serious one. In general the more serious cases showed the higher values.

The condition of all the subjects, at the one-year follow-up, is shown in Table 3. Of the definite cases, 5 improved, 4 remained the same and 1 worsened. Two patients who had ANA at reciprocal titers of 10 to $80 \mathrm{had}$ improved during the one-year observation period without any symptoms of connective tissue diseases. Of the probable cases, 7 improved and 5 remained the same. Among the controls, significant fatigue developed in 1 case, the others were unchanged.

Examples of antibody titers and lymphocyte phenotype analysis in two definite cases, during the one-year study period are shown in Table 4 . We selected case No. 1 and No. 7 to demonstrate possible antibody courses. Case No. 1 improved and No. 7 deteriorated.

Case No. 1 had suffered from significant fatigue for

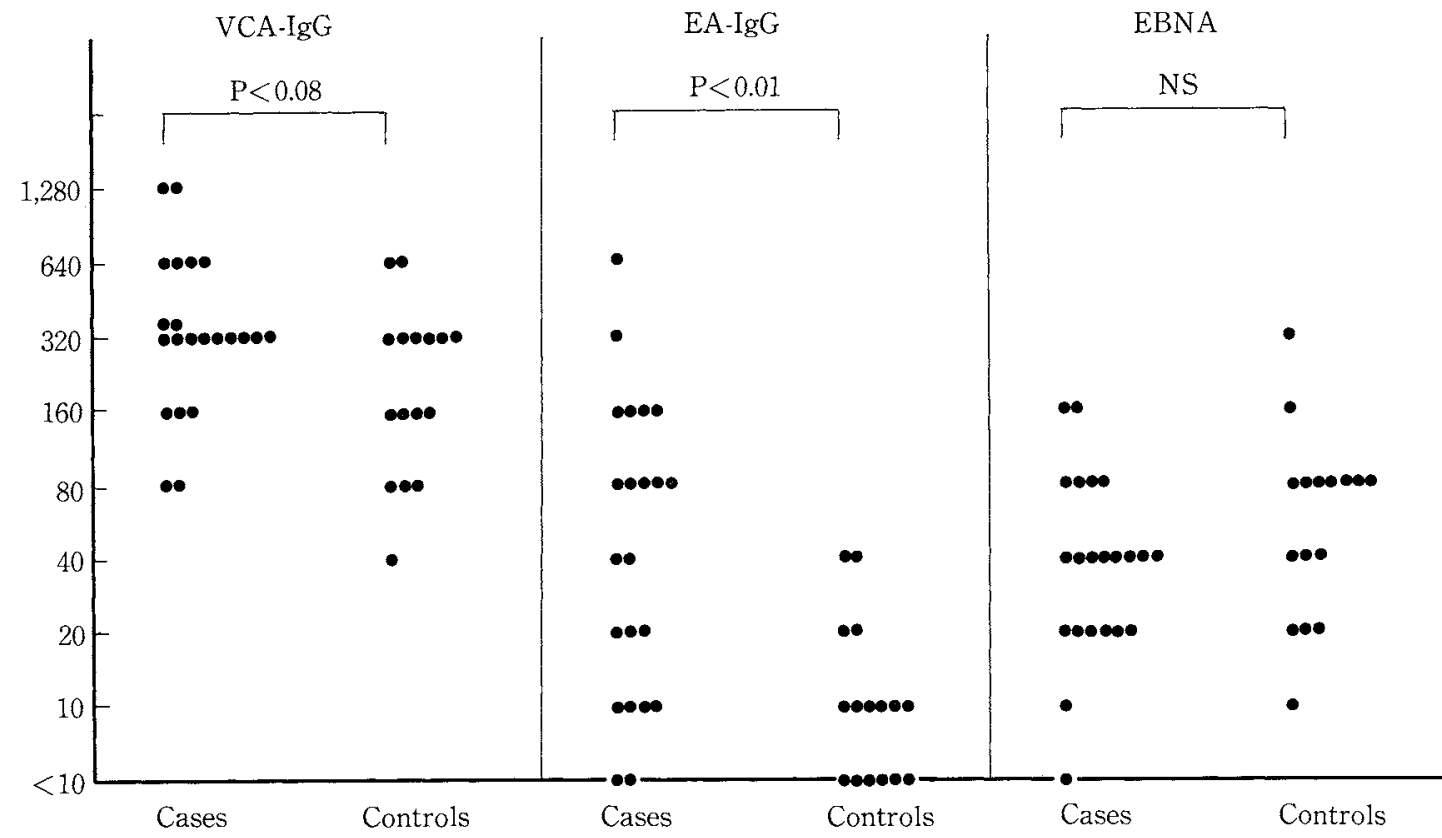

Fig. 1. The comparison of three EBV-antibodies (VCA-IgG, EA-IgG, EBNA) between all cases and controls. The ordinate is the reciprocal titers of the antibodies. There were the significant differences in VCA-IgG and EA-IgG. NS: not significant 


\section{Kawai and Kawai}

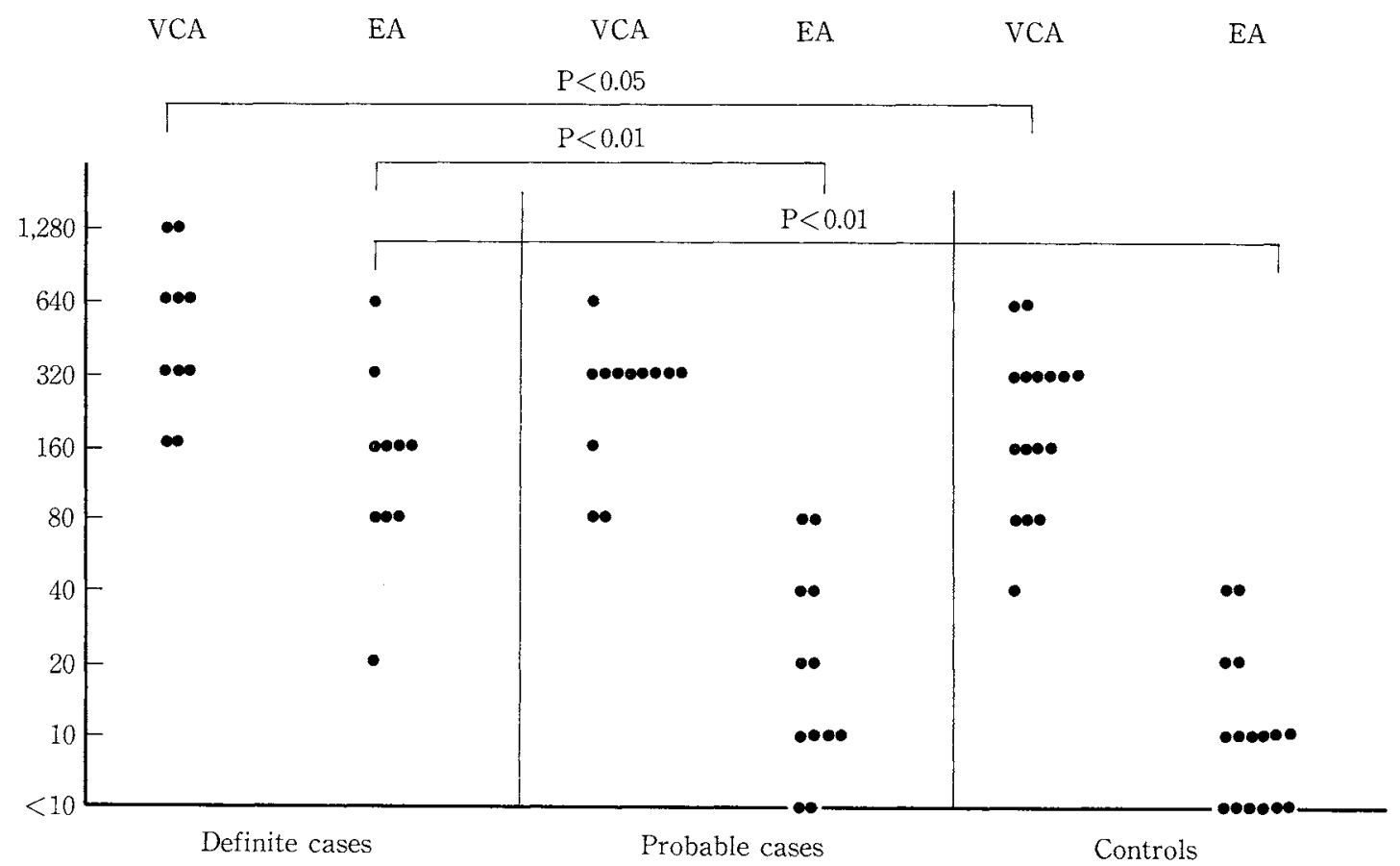

Fig. 2. The comparison of VCA-IgG and EA-IgG in definite cases, and probable cases and controls. The ordinate is the reciprocal titers of the antibodies. There were the significant differences in VCA-IgG between definite cases and controls. There were also significant differences in EA-IgG between definite cases and probable cases, and between definite cases and controls. EA: EA-IgG, VCA: VCA-IgG.

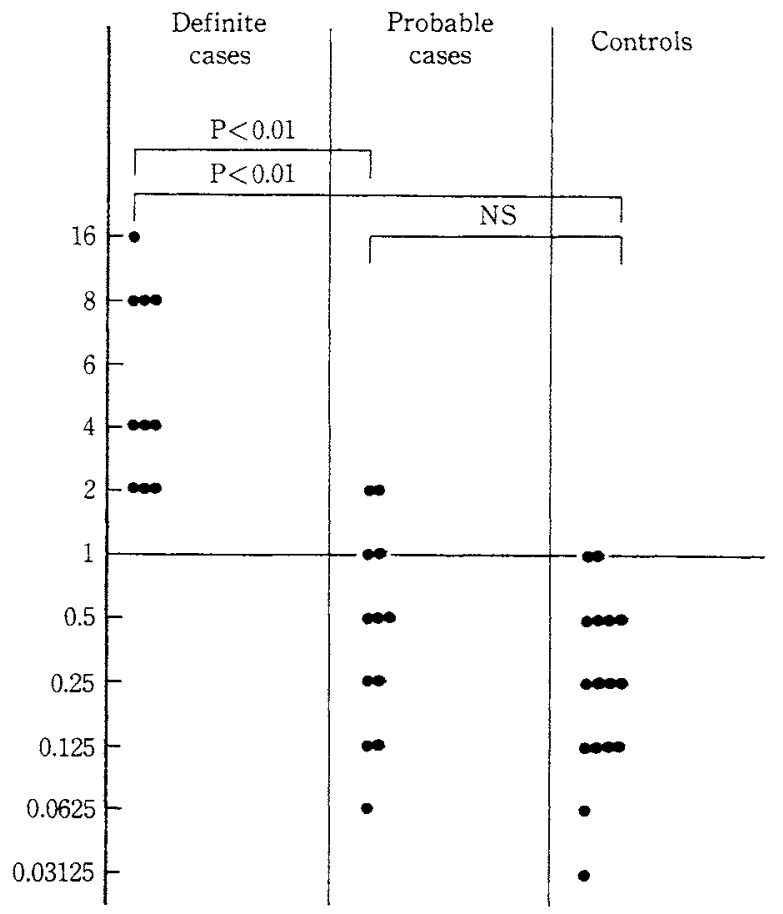

Fig. 3. The EA-IgG/EBNA ratio in definite cases, probable cases and controls. The ordinate is the EA-IgG/EBNA ratio. In order to calculate the ratios, antibody titers of less than 10 were regarded as 10 . The difference in the mean titers of the EA-IgG/EBNA ratio between the definite cases and probable cases was significant $(p<0.01)$. The difference between the definite cases and controls was also significant. The difference between the probable cases and controls was not significant.
Table 3. The Outcome of All Subjects at One-yr Follow-up

\begin{tabular}{lccc}
\hline & Improved & Unchanged & Worsened \\
\hline $\begin{array}{c}\text { Definite cases } \\
(\mathrm{n}=10)\end{array}$ & 5 & 4 & 1 \\
$\begin{array}{c}\text { Probable cases } \\
(\mathrm{n}=12)\end{array}$ & 7 & 5 & 0 \\
$\begin{array}{c}\text { Controls } \\
(\mathrm{n}=16)\end{array}$ & 0 & 15 & $1 *$ \\
\hline
\end{tabular}

* Significant fatigue developed in this case.

3.2 years, after an infectious mononucleosis-like disease. She underwent a psychiatric consultation and was treated symptomatically with medication. Her fatigue is now almost fully resolved, however, she has now developed infrequent premature ventricular contractions. Her EA-IgG/EBNA ratio has fallen from 4.0 to 2.0 and the $\mathrm{CD} 4 / \mathrm{CD} 8$ ratio from 1.8 to 1.1 .

Case No. 7 had suffered from chronic fatigue for 22 years. She had no history of an infectious mononucleosislike illness. Her treatment was identical to that of case No. 1, however, she did not recover from her chronic fatigue. Her EA-IgG/EBNA ratio has continued at a high level (8.0); CD4/CD8 ratio has also continued at a

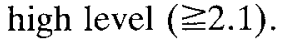


Chronic Fatigue Syndrome and EB Virus

Table 4. Two Examples of Antibody Titers and Lymphocyte Phenotype Analyses, During the One-yr Study Period

\begin{tabular}{|c|c|c|c|c|c|c|c|c|c|c|}
\hline Patients & Date & $\begin{array}{l}\text { VCA- } \\
\operatorname{IgG}\end{array}$ & $\begin{array}{l}\text { EA- } \\
\text { IgG }\end{array}$ & EBNA & $\begin{array}{l}\text { EA-IgG/ } \\
\text { EBNA }\end{array}$ & $\begin{array}{l}\text { Lymphocyte } \\
\mathrm{N} / \mathrm{mm}^{3}\end{array}$ & $\begin{array}{c}\mathrm{CD} 4 \\
\mathrm{~N} / \mathrm{mm}^{3}\end{array}$ & $\begin{array}{c}\mathrm{CD} 8 \\
\mathrm{~N} / \mathrm{mm}^{3}\end{array}$ & $\begin{array}{l}\mathrm{CD} 4 / \\
\mathrm{CD} 8\end{array}$ & Condition \\
\hline \multirow{3}{*}{$\begin{array}{l}\text { Case } 1 \\
q \\
34 \text { yrs }\end{array}$} & 89.7 .26 & 640 & 160 & 40 & 4.0 & 2211 & 1083 & 597 & 1.8 & \\
\hline & 90.4 .26 & 320 & 80 & 80 & 1.0 & ND & ND & $\mathrm{ND}$ & ND & unchanged \\
\hline & 90.8 .9 & 640 & 160 & 80 & 2.0 & 2310 & 900 & 785 & 1.1 & improved \\
\hline \multirow{3}{*}{$\begin{array}{l}\text { Case } 7 \\
q \\
58 \text { yrs }\end{array}$} & & & & & & & & & & \\
\hline & 90.6 .7 & 80 & 160 & 20 & 8.0 & 1968 & 885 & 334 & 2.6 & unchanged \\
\hline & 90.11 .30 & 160 & 160 & 20 & 8.0 & 2080 & 977 & 457 & 2.1 & worsened \\
\hline
\end{tabular}

\section{Discussion}

Fatigue is a common and vague symptom encountered in daily practice. Unfortunately this complaint has not received the attention it deserves. In the past the patients who complained of chronic fatigue, without a detectable cause, were diagnosed to have a neurosis or affective disorder, depression in particular. There were no laboratory tests for determining chronic fatigue or a raliable method to quantify its degree. However, the working definition by Holmes et al (9) appears very useful to identify CFS among the patients with symptoms of fatigue. Here, according to this criteria, 10 definite cases of CFS were diagnosed from 22 fatigued cases.

The prevalence of chronic fatigue in the present patients $(1.9 \%)$ was considerably lower than that reported by Buchwald et al (7). Generally except in one report (10), CFS seems to occur more frequently in the U.S.A. than in Japan. However, a comparison between CFS in the U.S.A. and Japan is of questionable significance due to the difference in the criteria and patient clusters. In an Austrian community the point prevalence of CSF was 37.1 cases per 100,000 (14). In Japan the report on the prevalence of CSF in a community has not been reported at present.

Discretion must be used when interpreting EBV antibodies due to the poor analysis reproducibility within and among laboratories. Yagura et al (15) reported 27 healthy adults who all had high antibody titers of VCA$\operatorname{IgG}(10-320)$ and EBNA $(10-160)$. However, only two had low titers of EA-IgG (10-20), while none had titers of VCA-IgM. The results of titers of these three antibodies in the present healthy controls had the same tendency (Fig. 1). Of the present 10 definite cases, 9 had higher antibody titers of EA-IgG (80-640) than both the probable cases and controls (Fig. 2). Of all subjects only case No. 3, who was the most seriously ill, had an antibody titer of VCA-IgM (20). It has been demonstrated by many authors that EA-IgG and VCA-IgM titers increase after endogenous reactivation of EBV or during a persistent infection episode $(2-4,16)$. An increase in EA-IgG in 9 out of 10 patients and VCA-IgM in seriously ill patients was observed in our study. This implies that EBV is one of the underlying etiological factors.

Antibody to EA increases in cases of either primary infection (17) or reactivation of EBV (16). Antibody to EA is transitory and disappears usually within several months after the onset of an infection (17). On the other hand, antibody to EBNA increases gradually, even after one year $(5,18)$ and its appearance usually correlates with resolution of an active infection (3). Jones pointed out the possible importance in an absence of antibody to EBNA in his fatigued cases who had positive titers of EA-IgG (3). From these reports, we proposed the comparison between the titers of EA and EBNA as an indicator of activation of EBV, and in the present cases we attempted to estimate the degree of fatigue by means of the EA-IgG/EBNA ratio. As a result, this ratio could demonstrate the significant difference between definite cases and probable cases, and the more serious cases showed higher values in general (Fig. 3). However the interpretation of the changes in the ratios during a given period needs further data (Table 4).

The cause of CFS is currently under debate. We suppose that immune aberrations expressed by specific patterns of EBV antibodies may be the cause of CFS. This immune aberration has been studied by many researchers $(3,4,19)$, however reports do not agree. We have also studied the absolute number of peripheral blood lymphocytes in the helper/inducer T-cell (CD4) and the suppresser/cytotoxic T-cell (CD8) subsets, as well as the CD4/CD8 ratio, in 6 definite cases. At the present time we can not determine if there is an abnormal tendency in lymphocyte phenotype analysis.

From the inquiry on the living environment and human relations of the 10 definite cases, we noticed that 6 patients had stressful life styles. We suggest that stress may play an important role in the cause of immune aberrations that reactivate $\mathrm{EBV}$ and finally result in CFS. 


\section{Kawai and Kawai}

From this study, it can be concluded that a relationship does exist between EBV and CFS. However, the true nature of CFS remains unknown and requires further investigation.

\section{References}

1) Kroenke K, Wood DR, Mangelsdorff AD, Meier, NJ, Powell JB. Chronic fatigue in primary care. J Am Med Assc 260: 929, 1988.

2) Tobi M, Morag A, Ravid Z, et al. Prolonged atypical illness associated with serological evidence of persistent Epstein-Barr virus infection. Lancet 1: 61, 1982.

3) Jones JF, Ray CG, Minnich LL, Hicks MJ, Kibler R, Lucas DO. Evidence for active Epstein-Barr virus infection in patients with persistent unexplained ilhess: Elevated anti-early antigen antibodies. Ann Int Med 102: 1, 1985.

4) Straus SE, Tosato G, Armstrong G, et al. Persistent illness and fatigue in adults with evidence of Epstein-Barr virus infection. Ann Int Med 102: 7, 1985.

5) Horwitz CA, Henle W, Henle G, Rudnick H, Latts E. Long-term serological follow-up of patients for Epstein-Barr virus after recovery from infectious mononucleosis. J Inf Dis 151: 1150, 1985.

6) Holmes GP, Kaplan JE, Stewart JA, Hunt B, Pinsky PF, Schonberger LB. A cluster of patients with a chronic mononucleosis like syndrome is Epstein-Barr virus the cause? J Am Med Assc 257: 2297, 1987.

7) Buchwald D, Sullivan JL, Komaroff AL. Frequency of chronic active Epstein-Barr virus infection in a general medical practice. J Am Med Assc 257: 2303, 1987.

8) Hellinger WC, Smith TF, Van Scoy RE, Spitzer PG, Forgacs P, Edson RS. Chronic fatigue syndrome and diagnostic utility of antibody to Epstein-Barr virus early antigen. J Am Med Assc 260: $971,1988$.

9) Holmes GP, Kaplan JE, Gantz NM, et al. Chronic fatigue syndrome: A working case definition. Ann Int Med 108: 387, 1988.

10) Manu P, Lane TJ, Matthews DA. The frequency of the chronic fatigue syndrome in patients with symptoms of persistent fatigue. Ann Int Med 109: 554, 1988.

11) Wessely S, Powell R. Fatigue syndromes: a comparison of chronic "post viral" fatigue with neuromuscular and affective disorders. J Neuro Neurosurg Psychiat 52: 940, 1989.

12) Lipsky PE. Rheumatoid arthritis. in: Braunwald E, Isselbacher KJ, Petersdorf RG, Wilson JD, Martin JB, Fauci AS, Eds. Harrison's Principles of Internal Medicine 11th Edit, McGrawhill, Inc., New York, 1987, p. 1423.

13) Henle W, Henle G, Horwitz CA. Epstein-Barr virus specific diagnostic tests in infectious mononucleosis. Human Pathol 5: 551, 1974.

14) Lloyd AR, Hickie I, Boughton CR, Spencer O, Wakefield D. Prevalence of chronic fatigue syndrome in an Australian population. Med J Aust 153: 522, 1990

15) Yagura H, Katsura Y, Funahashi S. Studies on the levels of specific antibodies to Epstein-Barr virus and heterophile antibody in the patients with infectious mononucleosis. Rinsho Byori 37: 164, 1989 (in Japanese).

16) Suyama CV. Endogenous reactivation of Epstein-Barr virus infections. J Inf Dis 135: 374, 1977.

17) Henle W, Henle G, Niederman JC, Klemola E, Haltia K. Antibodies to early antigens induced by Epstein-Barr virus in infectious mononucleosis. J Inf Dis 124: 58, 1971.

18) Henle G, Henle W, Horwitz CA. Antibodies to Epstein-Barr virus-associated nuclear antigen in infectious mononucleosis. J Inf Dis 130: 231, 1974.

19) Lloyd AR, Wakefield D, Boughton CR, Dwyer JM. Immunological abnormalities in the chronic fatigue syndrome. Med J Aust 151: 122, 1989. 